\title{
DOÑA MENCÍA LA ADELANTADA: UNA EXPEDICIÓN AL PARAÍSO
}

\author{
MARIA GABRIELLA DIONISI \\ Università della Tuscia \\ dionisi@unitus.it
}

Maria Gabriella Dionisi

Profesora de Literatura Hispanoamericana en la Universidad de la Tuscia de Viterbo, Italia. Ha realizado investigaciones sobre diferentes aspectos de la cultura paraguaya, participado en simposios internacionales, y publicado artículos y ensayos sobre los mayores escritores del Paraguay. En 2001 editó la primera traducción al italiano de una antología de cuentos paraguayos contemporáneos, y en 2005 tradujo la novela de Renée Ferrer Los nudos del silencio. Actualmente se ocupa de la relación entre Padres Salesianos e imaginario Patagónico.

\section{RESUMEN}

«Silenciada» por la historiografía oficial durante siglos, la vida de Doña Mencía Calderón de Sanabria, viuda del Tercer Adelantado del Rio de la Plata, ha sido rescatada del olvido gracias a la publicación de algunas novelas. Con el paso del tiempo, su figura, al principio glorificada como heroína de una empresa excepcional (cruzar en 1550 el Atlántico al mando de un pequeño «ejército» de mujeres destinadas a crear un hogar en Nuestra Señora de la Asunción) se ha transformado en un hito legendario de modernidad.

Palabras clave: Mencía Calderón, feminismo, expediciones, Río de la Plata.

\section{ABSTRACT}

Ignored by official historiography for centuries, the life of Doña Mencía Calderón de Sanabria, widow of the III Adelantado del Río de la Plata, has been rescued from oblivion, thanks to the publication of a few novels. As time has gone by, the image of her, initially glorified as a heroine who accomplished an exceptional enterprise (to cross the Atlantic in 1550 in charge of a little «army» of women destined to start a family at Nuestra Señora de la Asunción) has changed into a legendary example of modernity.

Keywords: Mencía Calderón, feminism, expeditions, Río de la Plata.

Cuando en 1931 Enrique de Gandía dictó una conferencia sobre «un hecho histórico de la época de Irala [que parecía] arrancado de [una] novela de aventuras» (1932, p. 117), abrió una brecha en la espesa capa que hasta aquel entonces había ocultado una página harto interesante de la historia.

Antes, nadie se había ocupado del tema, ni siquiera cronistas tan conocidos como Martín del Barco Centenera o Ruy Díaz de Guzmán se habían detenido sobre el argumento a pesar de que, especialmente el primero, muy probablemente tuvo la oportunidad de recoger noticias de primera mano al llegar a Asunción en 1575, por estar todavía con vida algunos testigos directos e indirectos de dicho aconte- cimiento. Pero ellos prefirieron describir -en este caso sí, con todo lujo de detalles- hazañas y peripecias de soldados y aventureros en sus viajes por el Nuevo Mundo, aludiendo, sin pormenorizar los modos, a la que se dio a conocer como la «expedición Sanabria».

Por contra, la ponencia del distinguido historiador, síntesis de una meticulosa investigación, de una atenta lectura de informes, cartas y textos de la época de la Conquista, dejaba constancia de una

verdadera expedición de mujeres españolas al Río de la Plata en el siglo XVI. Hecho de por sí rarísimo en la historia de la América Hispánica, pues los monarcas españoles, no sólo no fomentaban la emigración
Doña Mencía la Adelantada: una expedición al paraíso MARIA GABRIELLA DIONISI 


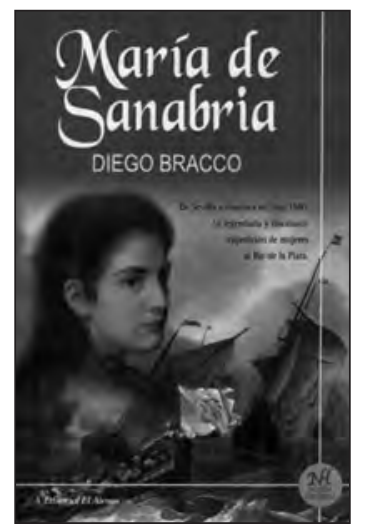

Diego Bracco, María de Sanabria. Portada.

1

Probablemente en el mismo periodo, Efraím Cardozo estaba escribiendo la que se proponía ser una obra monumental sobre la Historia del Paraguay, nunca concluida por su muerte. En ella las aventuras de la Adelantada estaban destinadas a tener un espacio propio.

2

Periodista, dramaturga y narradora, Josefina Cruz de Caprile publicó otras novelas históricas: El viento sobre el río (1950) Los caballos de Don Pedro de Mendoza (1968), La Condoresa (la segunda edición, de 1974, se titula Inés Suárez la Condoresa), El conquistador conquis tado: Juan de Garay (1973), Saavedra, el hombre de Mayo (1980).

Doña Mencía la Adelantada: una expedición al paraíso MARIA GABRIELLA DIONISI al nuevo mundo de las mujeres peninsulares, sino que prohibían, por medio de Reales Cédulas [...], que embarcaran mujeres en las naos de los descubridores (1932, p. 118).

A partir de los datos recogidos y de las informaciones que llegaban a la Península respecto a los escasos resultados obtenidos por Álvar Núñez Cabeza de Vaca para limitar el difundido concubinato entre españoles e indígenas existente en la recién fundada Asunción (1541), de Gandía elabora una hipótesis para justificar tan repentina trasgresión a la norma establecida: los Reyes habían tomado conciencia de que, para eliminar esta licenciosa situación, no servían reglas rígidas, sino mujeres solteras. Algo parecido ya se había verificado años atrás y en otra zona, cuando

en 1539 fray Valverde, obispo del Cuzco, [escribió] al rey pidiéndole que enviara «doncellas nobles de esas partes a esta tierra», ya que la mayoría de los españoles no querían casarse con indias pero estaban dispuestos a hacerlo con mujeres de la península (Gálvez, 1999, p. 49).

Por lo tanto, para tener éxito en la empresa de colonizar el área y, al mismo tiempo, imponer la austeridad castellana mediante una vida monogámica, olvidada por los españoles que habían descubierto en el pagano corazón de América los placeres del «Paraíso de Mahoma» (¡hecho curioso tras tantos años de lucha contra el infiel!), se necesitaban jóvenes dispuestas a crear hogar al otro lado del Atlántico.

Hipótesis (la de Gandía) y proyecto (el del Rey) nada descabellados, si consideramos que, en aquel periodo de transformación de los códigos comportamentales, la mujer seguía en su situación de clausura, ya que «sólo se le ofrecían [...] dos ocupaciones o empleos, y ninguno remunerado, salvo en gracias divinas: el matrimonio y el convento» (Plá, 1985, p. 30).

Así, no es atrevido pensar que, al verse privadas incluso de la posibilidad de desposarse, debido a la escasez en patria de varones célibes, causada por «las guerras [y] la emigración a América, en la cual abundaban más [...] los solteros que los casados», éstas «encarasen con excitación y revuelo de la fantasía el proyecto de viajar a encontrar compañero seguro» (Plá, 1985, p. 30). La esperanza de un brillante casamiento con quien, por «méritos y servicios», estaba destinado a formar parte de «la nueva nobleza americana que se estaba forjando» (Gálvez, 1999, p. 14), era sin duda alentadora para la mentalidad de la época.

De todo ello se desprende que las mujeres que debían llenar el «patache» del que hubiera tenido que ser el Tercer Adelantado del Río de la Plata, nada tenían que ver con la hueste de clandestinas que de vez en cuando cruzaban el Mar Tenebroso disfrazadas de varón para burlar las Cédulas Reales, ni con las compañeras de aquellos capitanes e hidalgos que participaron en la expedición de Don Pedro de Mendoza en 1536. Por ende, se trataba de jóvenes solteras procedentes de familias hidalgas, sobre todo de Extremadura, destinadas, con bendición real, a «conquistar a los conquistadores».

Con todo, nada de esto quedó reflejado en las relaciones más o menos oficiales que salieron a la luz en aquellas décadas tan efervescentes. Tampoco quedó constancia de otra peculiaridad del caso que vamos a analizar: con autorización real, y a pesar de existir un «presta nombre» varón, la empresa estaba a cargo de una dama viuda y madre de tres hijas.

El desinterés -incomprensible en un momento en el que el gusto por las aventuras y la exaltación por los viajes épicos estaban en boga-, siguió vigente durante los siglos siguientes; quizás por la dificultad de encontrar material apto para una reconstrucción fidedigna, o elementos concretos sobre los cuales ejercer la propia creatividad. $\mathrm{O}$ más bien, por la inevitable necesidad, al ponerse a relatar tal acontecimiento, de hacer añicos la afianzada imagen de una supuesta inferioridad femenina, y de una conquista y colonización española exclusivamente masculina.

Una lástima, según de Gandía, porque las características y la tipología de los protagonistas de esta historia hubieran podido ser un excelente «argumento para un novelista de fantasía» (1932, p. 118).

Lo cierto es que, hasta mediados del siglo XX, nadie se había animado a relatar las travesías de Doña Mencía y de las cincuenta (según algunos ochenta) mujeres que la acompañaron en el largo viaje desde Sevilla a Asunción, en búsqueda no de la «Tierra Incógnita» sino del «Marido Desconocido» (Plá, 1985, p. 37).

Sólo en $1960^{1}$ la novelista argentina Josefina Cruz ${ }^{2}$ escribió Doña Mencía, la Adelantada, obra que relata la sucesión de eventos 
ocurridos cuando -desvanecida la quimera del oro que mantuvo a los primeros conquistadores en un constante trajín hacia la Sierra de la Plata- comenzó la etapa fundacional de la colonia.

El trabajo para recolectar informaciones, como indicó en la nota «Al Lector», la obligó a visitar «Castilla, Andalucía, Extremadura y otras regiones de España»; a investigar «el Archivo de Indias en Sevilla y el Archivo privado de la familia Calderón» y más tarde, de regreso a América, a seguir rebuscando en «el Archivo Nacional del Paraguay y, en Buenos Aires, en la colección Gaspar García Viñas de la Biblioteca Nacional y en el Archivo Colonial del Museo Mitre». Por último, para «dar vida, emoción, realce a hechos auténticos», remontó «los ríos Paraná y Paraguay hasta la frontera de Bolivia» (Cruz, 1960, p. 11), y se adentró en la selva virgen.

De tamaña empresa salió una novela -anticipadora tanto de la gran estación de la narrativa del descubrimiento y de la conquista, como del actual boom de escritoras latinoamericanas que se han dedicado a temas históricos ${ }^{3}$ - en la que se hilvana la aventura de la que se considera la primera y única Adelantada del Río de la Plata de la que se tiene memoria (a pesar de que nunca fue titular de tal cargo, porque en aquella época era impensable asignar legalmente similar poder a una mujer).

El libro constituyó durante décadas un indispensable punto de referencia para quienes aspiraban a saber algo sobre el tema ${ }^{4}$. De hecho, como veremos a continuación, el primer intento posterior de desempolvar el argumento es el del escritor paraguayo Hugo Rodríguez Alcalá que, en su Romances de la Conquista (2000), le dedica un poema titulado «Doña Mencía y las cincuenta mujeres blancas», donde describe sin énfasis a la «dolida, mas no adredada» viuda, que decidió «cruzar los mares / y mandar en tierra brava», trayendo consigo a «cincuenta mujeres / todas de buena prosapia, / no sabemos si bonitas / mas de condición hidalga» (2000, pp. 57-58).

A partir de este momento, asistimos a un reavivarse del interés: en 2004 la editorial sevillana Espuela de Plata saca a la luz la novela de Eloísa Gómez-Lucena, Expedición al paraíso; en 2007 es publicada, por la madrileña Nowtilus, María de Sanabria del uruguayo Diego Bracco; por último, en 2010 se presenta una nueva versión de la historia con la novela
El corazón del Océano, de Elvira Menéndez, editada por Planeta.

Estos textos, diferentes entre sí por dimensión, estilo y enfoque, pero similares en su propósito de reivindicar el papel femenino en el descubrimiento y colonización del área, permiten reconstruir la insólita experiencia existencial de una «dama de pelo en pecho», como la definió Josefina Plá (1985, p. 29). Del mismo modo, su análisis permite bosquejar los distintos tipos de discursos que se han construido sobre estos hechos, pero siempre en pos del reconocimiento de la excepcionalidad de la empresa.

Para realizar dicho recorrido tenemos que partir de la reconstrucción histórica realizada por de Gandía -base reconocida por todos los autores-, y que indica como fecha de inicio 1547. Es éste el año de la firma de la Capitulación por la que el Rey autorizaba a Juan de Sanabria, rico caballero español, natural de Medellín, a armar una expedición de cinco navíos para trasladar a Asunción un gran número -para la época y las Leyes vigentes- de matrimonios y de mujeres solteras; fundar pueblos en lugares estratégicos para contrastar las pretensiones portuguesas sobre el Río de la Plata; y reestablecer el orden en Asunción tras la lucha entre Álvar Núñez Cabeza de Vaca y Domingo de Irala.

Según se lee en la nota de aceptación escrita por el mismo Juan de Sanabria, los preparativos para reunir a la gente empiezan después de una frustrada tentativa de evitar

la obligacion de llevar cien casados [ya que] no seria ni es cosa que conviene á la buena espedicion del descubrimiento y pacificacion, [por ser] mas ganosa de ir é pasar adelante donde conviene llegar, no llevando mugeres, ni teniendo necesidad de repartir la gente y dejarla en guarda en los lugares donde ovieren de quedar las mugeres é niños é gente que no fuere para poder seguir el dicho descubrimiento (Morla Vicuña, 1903, p. 46. La cursiva es mía).

Pero la muerte imprevista del recién nombrado Adelantado marcó un rumbo diferente a la entera organización. De hecho, las dificultades encontradas para llevar a cabo el proyecto, falto del poder carismático del
3

A este propósito es interesante el ensayo de Gloria Da Cunha (2004).

4

Incluso estudios sociológicos de cierto valor, como el de Idalia Flores G. De Zarza, o historiográficos como el de Efraím Cardozo, se refieren a la novela para hablar de este personaje, y Josefina Plá la define como "ensayo».

Doña Mencía la Adelantada: una expedición al paraíso MARIA GABRIELLA DIONISI 


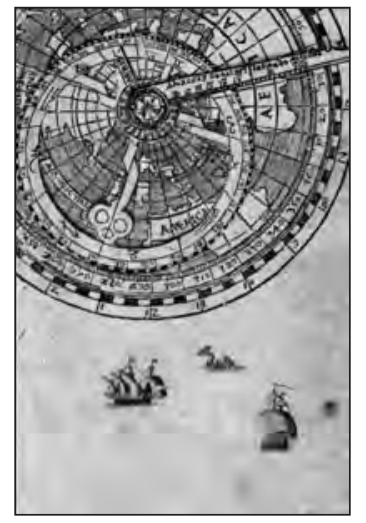

5

Una nueva edición, limitada, ha salido a la luz en Asunción en 1998, "a total beneficio -se lee en los Agradecimientos- de las obras que realiza» la Asociación Civil de Damas Paraguayas.

Doña Mencía la Adelantada: una expedición al paraíso MARIA GABRIELLA DIONISI noble extremeño, obligaron a su único hijo varón Diego, heredero legítimo del cargo, a dejar que su madrastra Doña Mencía Calderón de Sanabria asumiera el rol, y se pusiera a la cabeza de una parte de la flota. Tuvo que ser ardua la decisión, como se cuenta en la «Información» enviada por ella misma al Rey en 1564, ya que

vino a la ciudad de Sevilla la madre de Doña Mencia para llevarla a su tierra y la importunó e mandó que sacase su dote y hacienda que Juan de Sanabria había recibido cuando se casó con ella, [pero] visto por ella que sacando la dote no podía venir en efecto lo que el dicho su marido había capitulado con S. M. ni esta tierra ser socorrida e que muchas personas que habían gastado sus haciendas para venir la jornada quedarían perdidas, no quiso hacer lo que su madre mandaba, antes se partió y se vino con dichos navíos (Morla Vicuña, 1903, p. 50).

Por lo tanto, aceptando cumplir al pie de la letra lo que habían firmado los varones de su familia, el 10 de abril de 1550, partió de San Lúcar de Barrameda. Al mando de los marineros estaba Juan de Salazar, que ya había participado años atrás en la fundación de la ciudad de Nuestra Señora de la Asunción.

Durante el viaje, las pasajeras tuvieron que soportar sublevaciones, asaltos de corsarios, tempestades, enfermedades y, subraya en su narración doña Mencía, «mucho trabajo y necesidad de agua» (Morla Vicuña, 1903, p. 50). Todo esto prolongó sobremanera la navegación. Además, al llegar a la costa del Brasil, fueron detenidas por los portugueses. Obligadas a quedarse en San Vicente, fueron dejadas en libertad sólo en 1553, por intervención directa del Rey de España.

Era el inicio de otra aventura: llegar a Asunción, se lee en la Carta, "por tierra [y] a pie en que pasó grandes trabajos, necesidades y peligros» (Morla Vicuña, 1903, p. 51). Tardaron cinco meses en cubrir la distancia. Era el mes de octubre de 1555 cuando las mujeres entraron en la ciudad.

El viaje, que normalmente duraba cuatro meses de España a Santa Catalina, y otros cinco de Santa Catalina hasta Asunción, se había trasformado en una interminable odisea de cinco años.

A partir de estos datos se desarrollan las cuatro novelas, que poco varían en cuanto a respeto de la cronología.
La obra de Josefina Cruz, Doña Mencía, la Adelantada ${ }^{5}$, formada por treinta y un capítulos, un epílogo y una «breve biografía de los [cincuenta y siete] personajes históricos que figuran en este libro» (1960, p. 269), nace con el propósito evidente de no cuestionar las acciones de los personajes -actores que resultarán fundamentales para el progreso de la sociedad paraguaya-, sino de presentar la historia de una mujer «de pura cepa extremeña [y] de antiguo y claro linaje» (1960, p. 14), y de sus compañeras de (des)aventuras. En este sentido, la re-creación fidedigna del periodo se combina armónicamente con la fantasía para contar cómo pudieron haber ocurrido los hechos, rellenando los espacios vacíos de la información historiográfica gracias a la propia imaginación.

Narradora omnisciente, Cruz desde el incipit de la novela ofrece al lector una amplia contextualización, al presentar un ambiente en el que las relaciones humanas estaban condicionadas por valores básicos como la familia, el amor al terruño, el honor; pero que, al mismo tiempo, parece animado por una fuerte voluntad de superar los limitados confines de la propia comarca, ir hacia la aventura, y convertir en realidad los sueños de gloria y de riqueza.

Evitando caer en la fácil exaltación por una etapa considerada heroica durante largo tiempo, la autora se detiene en la descripción de las luchas, intrigas y traiciones que contraponen dentro y fuera de la Península a la flor y nata de la nobleza española. El cuadro histórico se anima con los debates en seno de la Corte sobre los peligros de perder las prometedoras ventajas de la imponente empresa ultramarina, que les obliga a encontrar un amplio abanico de soluciones -hasta descabelladas para el rígido orden español- que apacigüen los ánimos:

Hace algunos días el marqués de Mondéjar llegó a Sevilla. Está muy malhumorado pues no ha hallado quien quiera ocupar el puesto de Adelantado del Río de la Plata y teme que la expedición no se lleve a cabo. «Esta expedición no puede perderse! -exclama-En ella va mi prestigio de Presidente del Consejo de las Indias. ¿Más dónde hallar el hombre probo, fuerte, voluntarioso?» [...] La viuda de don Juan de Sanabria guarda en sí el señorío de los suyos. Un audaz pensamiento inquieta al Presidente [...] y se pregunta por qué ha de ser varón el que desempeñe el cargo de Adelantado [...] y se dice: «Si yo osara 
rectificar el Libro de las Partidas, nombraría a esta mujer Adelantado del Río de la Plata (Cruz, 1960, pp. 40-41).

La quiebra de una de las más enraizadas tradiciones de la Conquista, así como la apertura de un ámbito hasta aquel momento reservado a los hombres, a un "calificado séquito de damas y doncellas» (Cruz, 1960, p. 13) resultan, por consiguiente, fruto de la casualidad, de la urgencia. Por añadidura, no pueden ser interpretadas, parece recordar la autora, como un paso adelante en la evolución del papel femenino, ni tampoco como reconocimiento de su potencialidad.

Efectivamente, la autorización tenía como finalidad llevar a cabo una misión más bien «femenina»: recuperar para la moral cristiana a aquellos «temerarios castellanos [que], aislados de España», se habían abandonado a un libertinaje desenfrenado creando una «profusión de mestizos» (Cruz, 1960, p. 15); asentar la estirpe española y transformar «esa ciudad indiana [Asunción] en el más puro baluarte castellano» (Cruz, 1960 , p. 22), gracias al aporte de sangre española pura.

Mensajeras de la religión y de sus principios, guardianas de las tradiciones, futuras esposas y madres, no viajaban llevadas por la ansiedad de Juan de Garay de «abrir puertas a la tierra», o fundar poblaciones, sino que se las enviaba para «formar el núcleo biológico de la élite social» (Bethell, 1990, p. 109), y «transportar en lo doméstico todo el caudal cultural traído de España» (Gálvez, 1999, p. 169), quedando de facto otra vez atrapadas en sus roles tradicionales.

Pero, ¿cómo imaginar la reacción de estas doncellas ante las dificultades de un viaje por territorios desconocidos? ¿Cómo describir la vida de a bordo, las relaciones entre aquellas inéditas pasajeras y hombres versados en el «arte de marear»? ¿Según el cliché aceptado por el mismo Sanabria y por los cronistas de renombre que se habían referido a las mujeres "sólo como a un accidente de la empresa» (Plá, 1985, p. 11), a un estorbo más por ser débiles espiritual y moralmente? ¿ $\mathrm{O}$ más bien, desde una perspectiva reivindicativa del coraje y de la resistencia del gentil sexo? Josefina Cruz elige sin claudicaciones esta segunda opción, dejando que Doña Mencía y sus doncellas destaquen en las páginas por su temple y determinación.
La Adelantada, gracias a su férrea voluntad, no sólo aguanta todo padecimiento físico $\mathrm{y}$ «sufre con entereza el rigor del viaje y su ejemplo estimula a las mujeres que, pese al malestar que sienten, no profieren una queja» (Cruz, 1960, p. 84), sino también moral. La muerte de la hija menor, las dudas sobre la oportunidad de tal viaje, el hambre y el miedo durante el abordaje de los piratas franceses en el Golfo de Guinea no mellan su firmeza.

Este último episodio permite a la autora enaltecer al máximo el poder carismático de la altiva dama, cuya historia llega a conmover hasta (!) «al jefe de los piratas [que] con súbito respeto contempla la silueta de doña Mencía que está de pie en el castillejo del patache. Más que una mujer parece una leona que defiende a sus cachorros» (Cruz, 1960, p. 81).

Es la aceptación incondicionada de la tesis de un ataque corsario sin violaciones, que lleva a conformarse solamente con la entrega de todos los objetos de valor presentes en la bodega del navío, sostenida por Juan de Salazar,

en una Carta, todavía inédita, fechada en la laguna de Mbiazá, el 1 de enero de 1552, [en la que] refiere que la nao francesa «se levantó y arribó sobre nosotros, con muchas trompetas, vanderas y atambores» aterrorizando con sus disparos de artillería a las inocentes damiselas, y que sólo cuando los franceses, con gran sorpresa, oyeron «los lloros y gritos de las mujeres y niños» y vieron «cuan mal les respondíamos, porque ni artillería ni diez arcabuces, dejaron de tirar y quisieron saber que gente éramos (de Gandía, 1932, pp. 134-135).

Lo que pasó realmente es difícil imaginar, por ser vaga incluso la relación de Doña Mencía:

Muy Magnifico Señor.

Doña Mencía Calderon por mi y en nombre de Don Diego de Sanabria, Gobernador de las provincias del Rio de la Plata, por su Magestad, digo: que viniendo yo en este navio Patax con la gente de guerra y pobladores [...] se ofreció que aportando con temporal contrario hacia la costa de Malagueta, pareció cierta vela francesa [...] que por fuerza y contra nuestra voluntad hizo amainar las velas [...] y apoderándose de nosotros con ventajas [...] nos hizo fuerza é robó lo que por bien tuvo con poco temor de Dios y a su Magestad, y aunque muchas veces fueron requeridos nos dejasen en paz por ser armada de su S. M. y por su mandado enviada [...] no dejaron de bacer el dicho

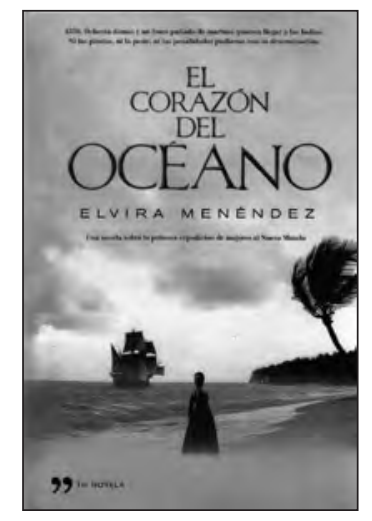

Elvira Menéndez, El corazón del océano. Portada.
Doña Mencía la Adelantada: una expedición al paraíso MARIA GABRIELLA DIONISI 


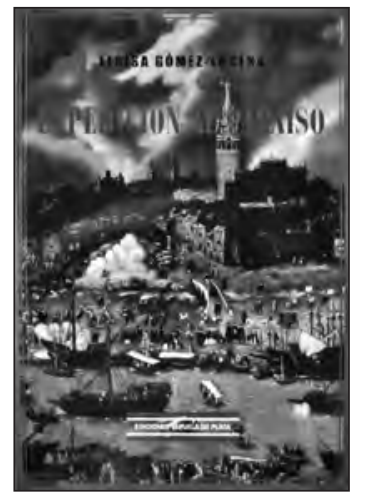

Eloisa Gómez-Lucena, Expedición al paraíso. Portada.

6

Bibliotecaria y documentalista, Gómez-Lucena inaugura con esta novela su actividad literaria.
Doña Mencía la Adelantada: una expedición al paraíso MARIA GABRIELLA DIONISI saco, antes pusieron gran escándalo y temores (Morla Vicuña, 1903, pp. 49-50).

En todo caso, la manifiesta exageración de Cruz, justificable por el corte romántico de la novela, se diluye en los capítulos en los que, al desear otorgar cierto halo de veracidad al texto -no olvidemos que Josefina Plá lo definió ensayo (1985, p. 39)-, se detiene en la descripción del paisaje, las costumbres de los indios y la situación política en Asunción. Ésta, sobre todo, resulta fundamental para ofrecer al lector mayor información sobre la necesidad e importancia de la expedición para la estabilidad política de la región.

En este sentido, el capítulo dedicado a la decisión de Irala -casi contemporánea a la llegada de las futuras «dueñas»- de casar a sus cuatro hijas mestizas con otros tantos capitanes españoles, explica la urgencia de evitar la creación de hogares mixtos, tan claramente percibida en España. Las bodas organizadas por el entonces Gobernador de Asunción, que formalmente debían servir para estrechar el «pacto de sangre» con los guaraníes, en concreto le garantizaban un propio círculo familiar, creando la que se conoce como «yernocracia».

Además, era evidente que la existencia de una capilla política paralela a la central, y el reconocimiento del mestizaje, formalizado por el mismo Irala en su testamento, con el que declaraba legítimos a los nueve hijos, nacidos con siete diferentes criadas indias, ponía en peligro no sólo el centralismo absolutista de la madre patria, sino también las normas que reglamentaban la encomienda, uno de cuyos privilegios residía precisamente en el derecho hereditario.

Por lo tanto, el énfasis en las bodas -base para reestablecer el tejido social español-que se celebraron tanto durante como tras la conclusión del viaje, al igual que los nacimientos, no sirven para dar brillo y salpicar la novela de acontecimientos felices, sino para subrayar la súbita realización del proyecto. Es un modo más para apoyar el mito fundacional estrechamente vinculado a España, así como queda demostrado en el Epílogo:

Venticinco años han pasado desde el arribo de doña Mencía a la Asunción [ahora] cabeza de las fundaciones [...] Doña Mencía ha envejecido [pero] muchos nietos crecen junto a ella [...] sabe que sus días están contados pero ya no le importa. Ella plantó su se- milla en el Nuevo Mundo y los hijos de sus hijos se volcarán como un torrente por las selvas, los ríos, las montañas y las pampas (Cruz, 1960, pp. 257-267).

Palabras que no dejan dudas sobre el aporte positivo, civilizador de la armada de mujeres, y que reflejan lo afirmado con gracia, pero con determinación, por Doña Mencía en su Carta:

La gente que á esta ciudad delante vino como la demas gente que despues con Doña Mencia á ella vinieron, hicieron á esta ciudad de la Asuncion gran provecho, por ser como eran mancebos para mucho é bien armados y muchos casados con mugeres españolas muy honradas, que fué grande utilidad para el enseñamiento de muchas mozas que en la tierra había (Morla Vicuña, 1903, p. 51).

En la misma pauta se colocan los trabajos que en esta última década -tan comprometida a bucear en la historia latinoamericana para rescatar figuras de gran importancia en el pasado- han elegido como argumento al personaje de la Adelantada. Todos se presentan como textos que pretenden desempeñar una función divulgadora, quizás para satisfacer a un nuevo público de lectores ávidos de cualquier ficción histórica.

Resultan, como consecuencia, novelas de tesis bastante clásicas, si se excluyen algunos pequeños intentos de utilizar formas alternativas de narración. Asimismo, las variantes que las distinguen se pueden medir en base al grado de incidencia de lo demostrable y lo inventado o modificado; a través de la presencia más o menos marcada de personajes reales que se contraponen a otros de pura fantasía.

En todo caso, sin poner en tela de juicio lo estratificado por la tradición y utilizando las mismas fuentes documentales, reconstruyen, cada una a su manera, las vicisitudes «silenciadas» de Doña Mencía y de sus compañeras. Sacándolas de la sombra, las elevan a la categoría de sujetos, dando mérito a las penurias, los miedos, las glorias y los fracasos que afrontaron durante su largo viaje. Trasformándolas, a menudo, en personajes demasiados leyendarios para ser reales.

En el caso de Expedición al paraíso de la malagueña Eloísa Gómez-Lucena ${ }^{6}$, la misma estructura apunta a reivindicar para la viuda de Juan de Sanabria un espacio propio e incuestionable en la Historia. 
Construido a imitación de las crónicas de Indias (evidente en el uso de títulos explicativos y didascálicos), pasando de la objetividad a la fantasía, el texto se propone como un «relato entreverado de sueño y realidad» (Gómez-Lucena, 2004, p. 19), una especie de crónica-memoria. Pero los términos tradicionales de este género narrativo resultan subvertidos, puesto que el papel activo de cronista está asignado a una mujer.

Rememorando la importante función informativa -por presentar la otra cara de la medalla- que siguen teniendo los pocos testimonios escritos por mujeres, la autora, incluso en lo formal, contrapone el derecho y la posibilidad de escribir una experiencia vivida en primera persona, a la afasia a la que estaban condenadas las mujeres en aquel entonces.

El discurso historiográfico y la ficción se entremezclan por medio de la declarada compilación de dos versiones de la historia: la oficial -el relato escueto de las distintas fases del viaje, mezcla calculada de «realidad, moderada imaginación y abundante dosis de gloria» (Gómez-Lucena, 2004, p. 155); y la personal -el diario íntimo de la cronista, encargada de redactar las cartas de la Adelantada, de poner «en frases el pensamiento de doña Mencía [eligiendo] la frase más acorde al gusto de doña Mencía» (Gómez-Lucena, 2004, p. 297).

Gracias a esta doble perspectiva, la escritora logra hacer hincapié en el absoluto protagonismo de la que considera y presenta como una heroína. A tal fin elimina de la narración todo lo relacionado con la obligación a emprender el viaje, a asumir el compromiso de cumplir con lo establecido en la Capitulación firmada por su marido. Lo que le urge destacar es el temple extraordinario de esta viuda, quien

socorría a las mujeres, de la tolda a la cubierta y de babor a estribor, como si hubiera nacido en un barco. Lareda la llamaba la capitana, y los marineros lo imitaron a despecho de Juan de Salazar. Por su intrepidez, la tripulación situó a esta mujer de secano en el castillo de proa, en donde bajo su estandarte, dominaba el bullir de la cubierta. (Gómez-Lucena, 2004, p. 91)

Al definirla «la mujer más audaz de todos los tiempos» (Gómez-Lucena, 2004, p. 227), la retrata en las ocasiones más arriesgadas, en el patache contra los corsarios, como en la tierra firme, desafiando a indios caníbales y animales salvajes:

Doña Mencía se movía por la selva brasileña como entre los encinares extremeños, sin sorpresa ante la jerigonza de los volátiles ni pasmo ante los frondosos parajes. Atenta tan solo a los obstáculos que le salían al camino en el cumplimiento de su misión (p. 228).

No cabe duda de que el paso de la novela histórica de tesis a la de aventura es muy breve, y el tema, como insinuó de Gandía, da para tanto.

Es lo mismo que ocurre en María de Sanabria del uruguayo Diego $\mathrm{Bracco}^{7}$, publicada en España en $2007^{8}$. En este caso, el proceso de manipulación del personaje y de su vida es extremo. Presentada como una novela de «pasión e intriga», por ser rica de acción, delaciones, asesinatos, violaciones, cuenta la historia desde una perspectiva diferente, al atribuir a María, la hija mayor de doña Mencía, lo vivido por la madre.

A su vez, esta última pierde totalmente las características con las que había sido retratada anteriormente, para convertirse en una mujer resignada, titubeante, incapaz de tomar decisiones, víctima de un poder masculino agobiante, de un marido acostumbrado a insultarla y «golpear[la] con método» (Bracco, 2007 , p. 51). Pero ¿cuál es la razón y la finalidad de dicho cambio?

Resulta evidente que la nueva versión no se debe a haber encontrado pruebas documentales originales, puesto que la bibliografía utilizada es la misma de las escritoras anteriores. Tampoco es muestra de una voluntad de parodiar o desmentir radicalmente dichas narraciones.

Por contra, estamos ante una revisitación de la Historia desde una perspectiva moderna -tan propia de la llamada «nueva novela histórica»- que deja la máxima libertad al autor para hablar de problemas que afectan todavía a nuestro mundo contemporáneo: la violencia de género, la lucha cotidiana por la eliminación de antiguos tabúes, la dificultad de gestionar el poder y el vívido afán de gloria, el precario equilibrio entre estos sueños de grandeza (normalmente masculinos) y el deseo de conservar la propia feminidad.

Desafiando el patrón tradicional, Bracco asigna a María -joven, rebelde, ambiciosa, batalladora, hábil y oportunista- el papel de mujer ansiosa de romper el cerco opresor impuesto por
7

Autor de ensayos académicos, ha publicado dos novelas históricas: Memorias de Ansina, y El mejor de los mundos.

8

En 2008 fue traducida al portugués y publicada por la editorial Record, y en 2009 El Ateneo de Buenos Aires realizó una nueva edición en español.

Doña Mencía la Adelantada: una expedición al paraíso MARIA GABRIELLA DIONISI 
Guionista de cine y de teatro, es escritora de cuentos infantiles.
Doña Mencía la Adelantada: una expedición al paraíso MARIA GABRIELLA DIONISI la sociedad machista, para seguir una dirección propia. Y su viaje hacia las Indias, conocidas a través de las relaciones de Álvar Núñez Cabeza de Vaca o de Hernán Cortés, resulta justificado por la certeza de poder construir al otro lado del Océano una nueva vida:

me ha movido la necedad de los hombres. [...] Por la gloria he recorrido este camino. Por la inmensa admiración hacia los que protagonizaron grandes hechos. Para que el presente y la posteridad tuvieran noticias de mí. Por ello me empeñé en buscar el poder (Bracco, 2007, p. 228).

El inédito enfoque, la creación de una heroína anticonvencional, que pone en segundo plano la que había sido hasta el momento la única protagonista de la gran aventura de Ultramar, constituye un ejemplo aislado, pero abre caminos a otros posibles usos de esta historia, así como demuestra el último texto publicado sobre el tema: El corazón del Océano de Elvira Menéndez?.

Aquí, la autora gallega elige la historia como detonante, perfecto para su propósito de describir una época tan rica de cambios, oportunidades, descubrimientos de lugares y costumbres. Por lo tanto, llena las seiscientas páginas que componen el libro con un sinfín de anécdotas ficticias creadas alrededor de personajes históricos reales, a fin de crear un cuadro verosímil, cuyo realismo anhela satisfacer el pacto establecido con el lector.

Aprovechándose de las potencialidades de la escritura, se detiene en los más nimios particulares para describir, con un uso hiperbólico de adjetivos y sustantivos, cómo iban equipadas las naves, cómo eran los trajes de las mujeres, qué mercancía estaba atestada en las bodegas de los barcos, etc...

En esta reiterada presentación de escenas de vida de a bordo o en tierra firme, entre el bullicio de una tripulación heterogénea, Doña Mencía es una más entre la multitud de personajes principales y secundarios que participan en un viaje caracterizado, como hemos visto, por un número infinito de dificultades.

Cada personaje tiene su papel definido, destinado a asombrar o conmover, como sucede en la mayoría de las novelas histórica publicadas en estos últimos años, más cercanas a los relatos de viajes y aventuras que habían azuzado la fantasía de los niños, que a las novelas históricas reivindicativas de un pasado interpretado como base del presente.
Sin embargo, y a pesar de haber perdido en estas últimas novelas su rol predominante, la Adelantada está destinada a salir de la oscuridad a la que parecía condenada.

De hecho, si lo preconizado por de Gandía en los años treinta del siglo pasado ha tenido su resultado, la idea expresada en 1962 por Pastor Urbieta Rojas ( $i$ Qué argumento magnífico [...] para los libretistas del cine mundial!», 1962, p. 21) tendrá en un próximo futuro su efecto. Puesto que nada escapa al ojo (y al poder) del Gran Hermano, el paso del desconocimiento, a la definitiva $-y$ tal vez corruptora- popularidad lo marcará definitivamente la ya prevista versión televisiva de la novela de Menéndez, elegida como guión para una miniserie de Antena 3.

\section{Bibliografía}

Bethell, Leslie (1990), Historia de América Latina, Barcelona, Crítica.

Bracco, Diego (2007), María de Sanabria, Madrid, Nowtilus.

Cardozo, Efraím (1959), El Paraguay colonial, Buenos Aires, [s.e.].

Cruz, Josefina (1960), Doña Mencía, la Adelantada Buenos Aires, La Reja.

Da Cunha, Gloria (ed.) (2004), La narrativa bistórica de escritoras latinoamericanas, Buenos Aires, Corregidor.

Gálvez, Lucía (2007), Mujeres de la Conquista, Buenos Aires, Punto de Lectura.

Gandía, Enrique de (1932), Indios y conquistadores en el Paraguay, Buenos Aires, Librería de A. García Santos.

Gómez-Lucena, Eloisa (2004), Expedición al paraíso, Sevilla, Espuela de Plata.

Menéndez, Elvira (2010), El corazón del Océano, Madrid, Planeta.

Morla Vicuña, Carlos (1903), Estudio bistórico sobre el descubrimiento y conquista de la Patagonia y de la Tierra del Fuego, Leipzig, F.A. Brockhaus.

Plá, Josefina (1985), Algunas mujeres de la Conquista, Asunción, Newprint Oficios Gráficos.

Rodríguez Alcalá, Hugo (2000), Romances de la Conquista, Asunción, Ingrapar s.a.

Urbieta Rojas, Pastor (1962), La Mujer Paraguaya, Asunción-Buenos Aires, Talleres Gráficos Lucania.

Zarza, Idalia Flores de (1987), La mujer paraguaya protagonista de la historia, Asunción, El Lector. 